\title{
Simulating combustion processes based on digital technologies
}

\author{
Marsel Kadyrov ${ }^{1}$, Maria Khabarova $^{1}$, Alexander Khabarov ${ }^{1}$, and Alexei Trinchenko ${ }^{1 *}$, \\ ${ }^{1}$ Peter the Great St. Petersburg Polytechnic University, Institute of Power Engineering and Transpor- \\ tation Systems, 195251, Politechnicheskaya st., 29, Russian Federation
}

\begin{abstract}
The thermal power plants (TPP) make a basis of powergeneration industry of the majority of countries. The global growth of power consumption and the policy of energy-saving demand to increase the efficiency of plants operation, which is, among others, determined by the technical level of steam-generating units. The up-to-date digital technologies make it possible to assess the efficiency of boiler furnace operation at the stage of boiler unit designing, its reconstruction or retrofitting and upgrading. Developed in the article are the algorithm, mathematic model and computer program of calculating diffusion-kinetic process of combustion of D-grade Donetsk coal in the coal-dust flame of boiler E230-14,0-520. The assigned tasks have been solved by using theoretical methods of analysis, the capabilities of devices of computer-aided calculations have utilized for visualization of results. The considered digital approach to solving technical tasks makes it possible to meet the current and future challenges.
\end{abstract}

\section{Introduction}

The goal of the energy policy of country according to the energy strategy of Russia for the period up to 2030 is the maximum efficient use of natural energy resources and potential of the energy sector for steady economic growth, increase of quality of life of the country's population and contribution to strengthening its foreign-economic solutions.

The thermal power plants (TPP) make a basis of power-generation industry of Russia with the share in the structure of the installed power of the industry as of 2017 equal to $58.6 \%$. The share of TPP operated on coal equals $27.5 \%$. The efficiency of TPP operation depends to a great extent on the technical level of the main equipment, to which the steam boilers belong too.

One of the priority principles of building the power industry of future is the concept of Internet of Energy (EnergyNet), which is on the agenda of the National Technological Initiative of Russia (NTI). The new capabilities of the power industry of future are determined, among others, by such NTI direction as digital designing and simulation. It is necessary to secure the efficient energy generation apart from building reliable and flexible networks. Building of design calculations for plants equipment with the use of exclusively standard methods downloads a definite uncertainty into result of designing, when

\footnotetext{
*Corresponding author: trinchenko@spbstu.ru
} 
simulation with the use of digital technologies makes it possible to more accurately predict the efficiency of units operation. Most frequently the description of some physical processes is replaced with a number of correction factors. The insufficient consideration of the problem of fuel combustion process in polifraction flame of the steam power-generating boiler at the stage of designing can bring about in practice an excessive consumption of fuel, for instance, caused by mechanical underburning and, as a result, it entails the price growth for electric energy for consumers. Otherwise, the uprating of heat losses from mechanical underburning will cause a growth of capital expenditures.

The burning process will be determined by complex physical and chemical phenomena $[1,2]$ related to fuel burning in the furnace chamber of steam boiler. A process of forming a mixture of fuel and oxidizer is attributed to the main physical processes accompanying conversion of fuel internal energy into heat. The temperature and concentration of reacting substances belong to chemical factors exercising key influence on the fuel burning parameters. The complex fields of velocities, concentrations and temperatures can be observed in the furnace devices of steam, which determine in combination the kinetics of chemical transformations.

The purpose of the work is the investigation of process of combustion of particles of Dgrade Donetsk coal in the coal-dust flame of boiler E-230-14.0-520.

The following problems have been considered and solved in the process of investigation:

- Model and methods of determining velocities of gas and air flows in the steam boiler furnace chamber have been developed. The characteristic flow zones and the resulting field of velocities have been determined, which utilization is possible for calculating paths of movement of burning coke particles of a variable mass. The model helps obtain vector $\vec{W}$ in any point of furnace chamber and close the balance of flow rates in the cross sections of along coordinate axes.

- Taking into account the process stage character, the burning of coal particles of polifraction fuel moving in the flow of gases has been calculated, the paths of movement thereof in the furnace have been acquired;

- Dependences of changing size, density and mass of coal particles vs. time have been determined;

- Assessments of fuel mechanical underburning have been carried out.

\section{Model of flame burning in boiler furnace}

A model of burning process based on the diffusion and kinetic theory of burning is capable of changing quality (solid fuel type and composition, its grind, etc.) and quantity characteristics of the process (fuel consumption, velocity of burner air, etc.) making it possible to perform analysis of duration of individual stages of combustion process as well as quantitative evaluation of mechanical incompleteness of fuel burning in the furnace chamber.

A profound understanding of burning processes in power-generating units is required for practical calculations of the burning process at its different stages. In order to solve the problem of solid fuel particle burning, a definite process schematization has been adopted. The process is broken into relatively independent stages: particle heating until volatile matter yields or gets ignited, combustion of volatile matter around particle and combustion of residual coke consisting of carbon and ash. The stage of coke carbon burning is the most durable for coal dust and makes up to $90 \%$ of total time of particle burning. 
The duration of initial stages is determined with respect to empirical-formula dependences suggested by V. I. Babiy [3]:

$$
\begin{aligned}
& \tau_{\text {пр }}=-0.384 \cdot \frac{c_{\mathrm{y}} \cdot \rho_{\mathrm{u}} \cdot \delta^{2}}{\mathrm{Nu} \cdot \lambda_{\text {г }}} \cdot \lg \left(1-Q / Q_{\max }\right) \\
& \tau_{\text {в.л. }}=k_{\text {в лл. }} \cdot 5.3 \cdot 10^{14} \cdot T_{\text {г }}^{-4} \delta^{0.8} \\
& \tau_{\text {глл. }}=k_{\text {г.л. }} \cdot 0.5 \cdot 10^{6} \cdot \delta^{2}
\end{aligned}
$$

where, $c_{\mathrm{\Psi}}$ - specific heat capacity of fuel dry mass, $\mathrm{kJ} /(\mathrm{kg} \cdot \mathrm{K}) ; \rho_{\Psi}-$ initial particle density, $\mathrm{kg} / \mathrm{m}^{3} ; \delta$ - size of particle of fraction under consideration, $\mathrm{m} ; \mathrm{Nu}$ - thermal Nusselt criterion; $\lambda_{\Gamma}$ - heat conductivity, $\mathrm{kW} /(\mathrm{m} \cdot \mathrm{K}) ; Q / Q_{\max }$ - ratio of amount of heat absorbed by a particle to the amount maximum possible at this gas temperature; $T_{\mathrm{\Gamma}}-$ gas flow temperature, $\mathrm{K} ; k_{\text {влл. }}, k_{\text {глл. }}-$ trial coefficients.

Determination of gas temperature level by height of the boiler furnace chamber E-23014.0-520 (Fig. 1) has been carried out with the use of dependence suggested by A. M. Gurvich and A. G. Blokh. The temperature level variation by furnace height features a characteristic view (Fig. 2), and is described by the following dependence:

$$
\theta(\mathrm{z})=\frac{\alpha}{\beta-\alpha}\left(e^{-\alpha z}-e^{-\beta z}\right)
$$

where, $\mathrm{z}$ - relative distance from fuel inlet point; $\alpha=22.78, \beta=0.85$ - calculated parameters characterizing, accordingly, the intensity of heat radiation in case of fuel burning out and intensity of heat transfer to heating surfaces [4].

The combustion of coke carbon is a heterogeneous process determined by both kinetics of carbon particle burning and diffusion transfer of oxygen and combustion products. The result of simultaneous character of these processes is a definite distribution of concentrations of oxygen and combustion products at the burning surface.

In order to solve the problem of carbon particle burning, a concept of "reduced film", an area of strongly pronounced gradients of concentrations has been applied. The main types of gas reacting with the coke carbon include oxygen $\left(\mathrm{O}_{2}\right)$, carbon dioxide $(\mathrm{CO})$ and water steam $\left(\mathrm{H}_{2} \mathrm{O}\right)$. According to [5] the following basic resultant reactions take place at the particle external surface and at the surface of pores (thermal effect in $\mathrm{kJ} / \mathrm{mole}$ ):

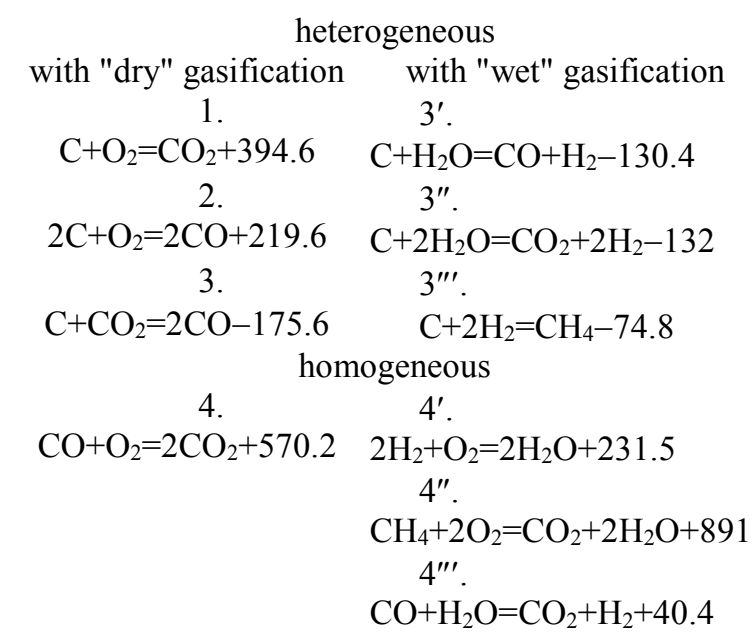


A scheme with the non-burning boundary layer is characteristic for the coal-dust fuel burning, when the diffusion processes only take place within the limits of a given film, while the oxide of carbon and hydrogen being generated as a result of carbon interaction with water steam and oxygen go beyond the boundaries of the given film and burn in the gas flow. A characteristic pattern of distribution of concentrations of reacting components at the surface of burning carbon particle is shown in Fig. 3.

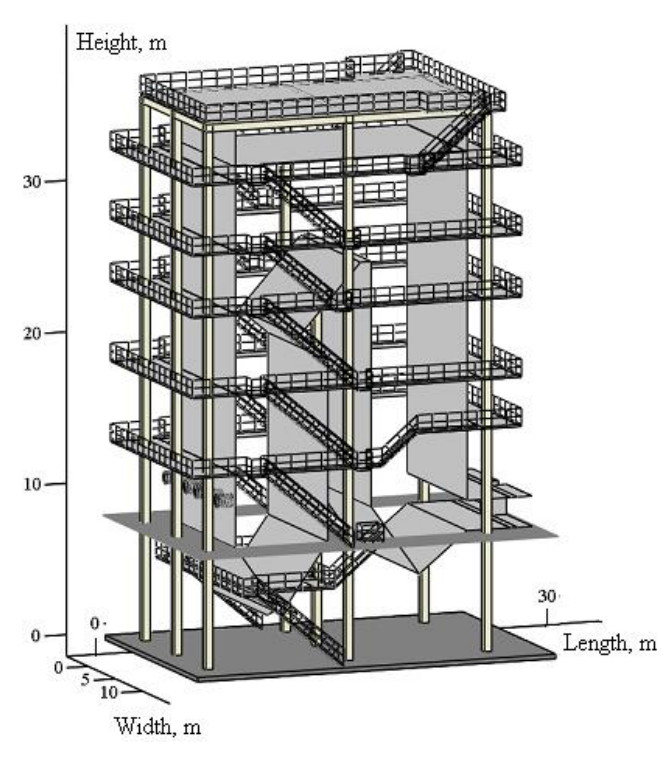

Fig. 1. Design model of boiler E-230-14.0-520

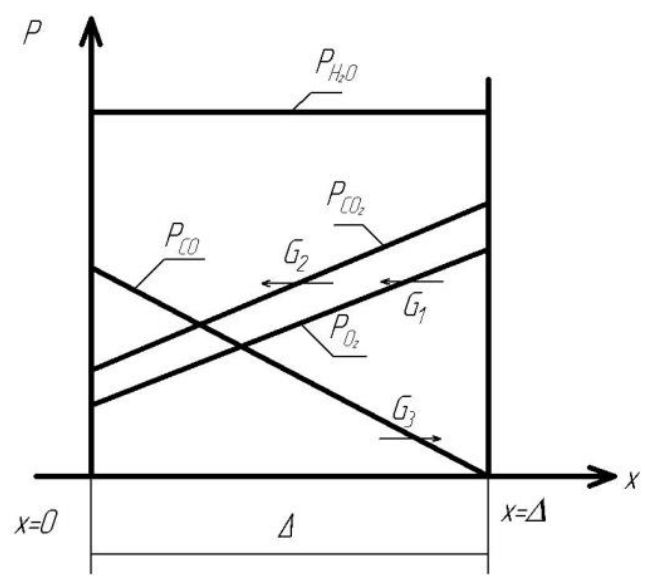

a

Fig. 3. Distribution of partial pressures (a) and flows (b) of components in a given film

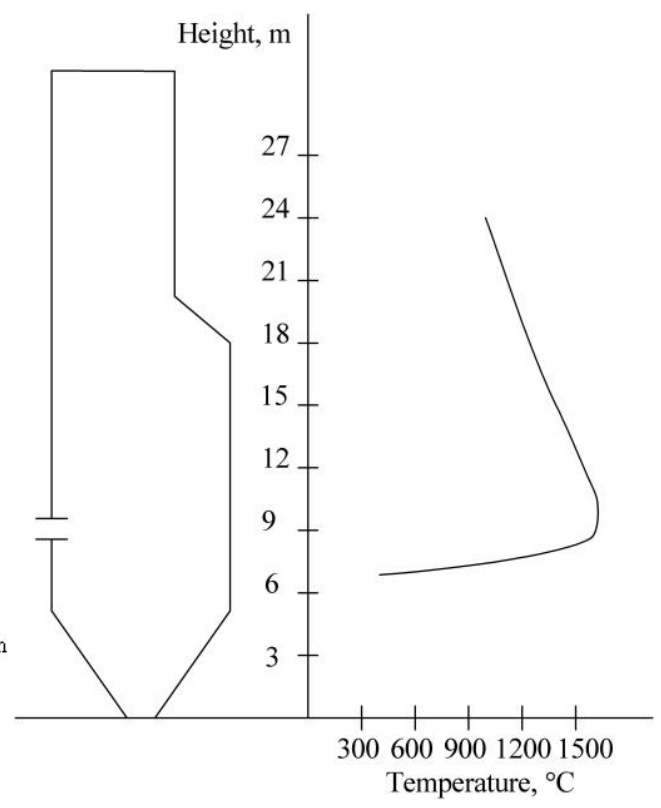

Fig. 2. Distribution of temperature (T) by height of furnace chamber $(\mathrm{H})$

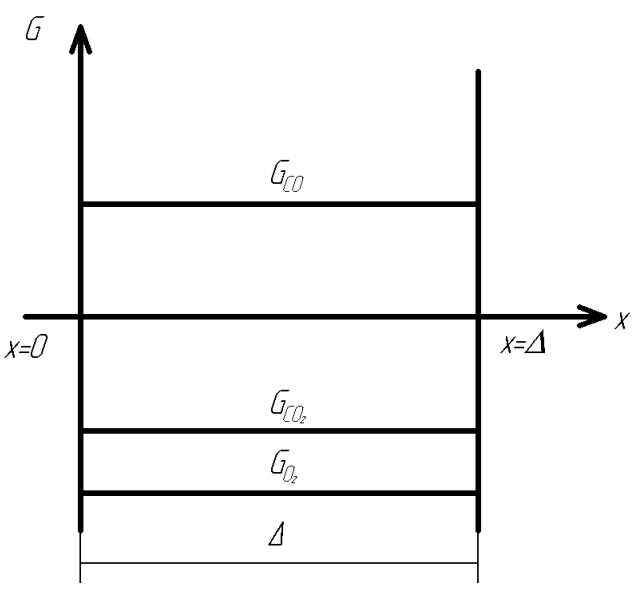

b 
The rate of carbon burning out taking into consideration the stoichiometric relationships (actual reactions):

$$
G_{\mathrm{c}}=1 /(R T)\left[\left(k_{1}+2 k_{2}\right) p_{10}+k_{3} p_{20}+k_{3^{\prime}} p_{50}\right],
$$

where, $R=8.31 \mathrm{~J} /(\mathrm{kmole} \cdot \mathrm{K})$ - universal gas constant value; $T$ - temperature by height of furnace chamber, $\mathrm{K} ; k_{\mathrm{i}}$ - constant rate of i-reaction, $p_{\mathrm{i} 0}$ - pressure of $\mathrm{i}$-component at particle surface, $\mathrm{kPa}$.

The variation of constant values of chemical reactions rate vs. temperature conforms to Arrhenius dependence:

$$
k_{i}=k_{0 i} \cdot \exp \left[-E_{i} /(R T)\right]
$$

where, $k_{0}$ - pre-exponential factor of Arrhenius dependence (in $\mathrm{m} / \mathrm{s}$ for heterogeneous and $1 / \mathrm{s}$ for homogeneous reactions); $\mathrm{E}$ - apparent activation energy, $\mathrm{J} / \mathrm{mole}$.

In order to calculate a link of activation and pre-exponential factor, a "pole" suggested by S.M. Shestakov was used:

$$
\lg k_{0 i}=0.2 \cdot 10^{-4} \cdot E_{i}+2 .
$$

The consideration of combustion process from the diffusion-kinetic positions helped compile a system of differential equations, which solution are the sought-for values in the expression for carbon flow from the fuel particle surface $\left(G_{\mathrm{c}}\right)$ :

$$
\left\{\begin{array}{l}
d G_{1}=-k_{4^{\prime}} /(R T) p_{1} d x \\
d G_{\mathrm{i}}=-D /(R T) d^{2} p_{\mathrm{i}} /\left(d x^{2}\right) d x, \\
d G_{4}=d G_{1}=-2 d G_{5}
\end{array}\right.
$$

where, $G_{\mathrm{i}}$ - flow of i-component, kmole $/\left(\mathrm{m}^{2} / \mathrm{s}\right) ; k_{4^{\prime}}$ - constant value of reaction rate $4^{\prime} ; p_{\mathrm{i}}-$ pressure of i-component, $\mathrm{kPa} ; D$ - diffusion coefficient, $\mathrm{m}^{2} / \mathrm{s}$.

Variation of particle size in time (burning out) will be determined by formula [6]:

$$
\frac{d \delta_{\mathrm{i}}}{d \tau}=-\frac{2 \cdot M}{\rho_{\kappa}} \cdot G_{c},
$$

where, $M=12 \mathrm{~kg} / \mathrm{kmole}$ - carbon molar mass; $\rho_{\mathrm{K}}=900 \mathrm{~kg} / \mathrm{m}^{3}$ - coke density.

Processing of screening curve of design fuel (Fig. 4) has helped acquire sizes of particles, quality thereof, mass and initial surface area for every fraction. The distribution of particles between fractions is determined according to formula of Rosin-Rammler:

$$
R_{0 \mathrm{i}}=\exp \left(-b \cdot \delta_{0 \mathrm{i}}^{n}\right)
$$

where, $b$ - experimental factor characterizing the grind fineness; $n$ - polydispersity indicator characterizing uniformity of grain distribution.

In the process of combustion of fuel particles, in addition to changing the size, the density changes and, as a consequence, the mass changes too. The mass changes due to the changed density of particle at the stages of particle heating (before yield and ignition of volatile matter) and burning of volatile matter near particle. After beginning of particle burning out the density is considered permanent and equal to the density of coke, while the mass change takes place due to changing size of coal dust particle. The described character of changing characteristics for particles with size of $300 \mu \mathrm{m}$ is shown in Fig. 5. 

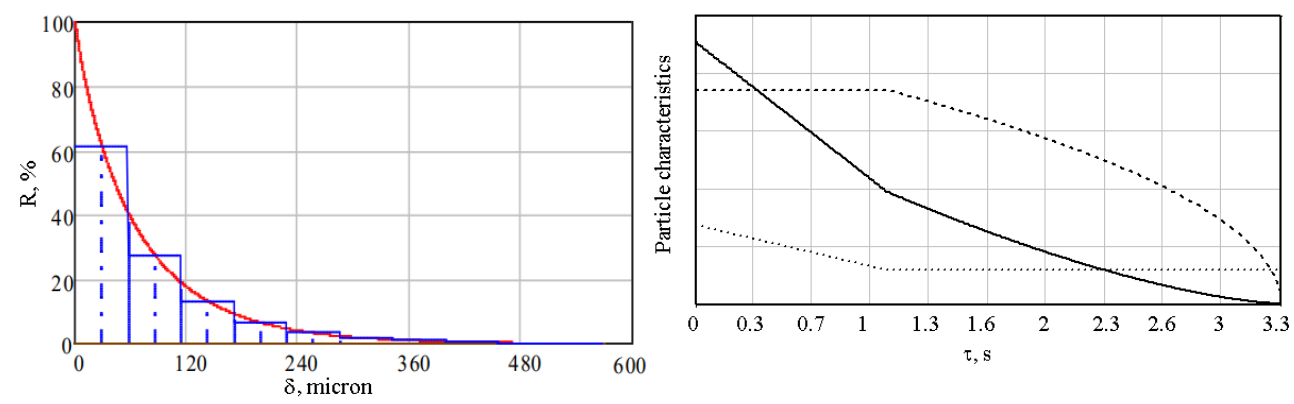

Fig. 4. Results of processing dust grain-size characteristic

Fig. 5. Variation of mass (-), density (…), size (----) of particle in time $\left(\delta_{0}=300 \mu \mathrm{m}\right)$

In order to calculate paths of motion of coal reacting particles, it is necessary to define the vector field of velocities of gas and air mixture in the steam boiler furnace chamber. The aerodynamics of combustion process determines conditions of fuel interaction with oxidizer. The purpose of calculating burning process is quite complex. A plane flow pattern has been adopted in this work with introduction of random distortion along the third coordinate. The initial area is being considered as a free immersed jet, its design dependences are shown in [5]. The upflow axis is S-shaped. As a result of uniting areas the vector field of velocities of gas and air flows in the section of furnace chamber has been obtained (Fig. 6).

In the course of particles moving in the gas flow it is customary to single out individual, the most significant factors: force of aerodynamic drag and gravity force of a particle [7-9]. Taking into account the variable mass for the flat pattern, it is possible to put down the equation of reacting particles movement in projections on the axis of $2 \mathrm{D}$ rectangular coordinate system [5]:

$$
\left\{\begin{array}{l}
\frac{d m v_{\mathrm{x}}}{d \tau}=\frac{c \cdot f \cdot \rho_{2}}{2} \cdot\left(w_{\mathrm{x}}-v_{\mathrm{x}}\right) \cdot \sqrt{\left(w_{\mathrm{x}}-v_{\mathrm{x}}\right)^{2}+\left(w_{\mathrm{y}}-v_{\mathrm{y}}\right)^{2}} \\
\frac{d m v_{\mathrm{y}}}{d \tau}=\frac{c \cdot f \cdot \rho_{\mathrm{z}}}{2} \cdot\left(w_{\mathrm{y}}-v_{\mathrm{y}}\right) \cdot \sqrt{\left(w_{\mathrm{x}}-v_{\mathrm{x}}\right)^{2}+\left(w_{\mathrm{y}}-v_{\mathrm{y}}\right)^{2}}-m \cdot g
\end{array} .\right.
$$

where, $V$ and $W$ - velocity of particle and gas flow, $\mathrm{m} / \mathrm{s} ; m, f$ - accordingly, mass and frontal area of a particle, $\mathrm{kg}$ and $\mathrm{m}^{2} ; \rho_{\mathrm{\Gamma}}-$ gas flow density, $\mathrm{kg} / \mathrm{m}^{3} ; c=f(\mathrm{Re})-$ coefficient of resistance of burning particles is calculated according to expression:

$$
c(\mathrm{Re})=\left\{\begin{array}{ll}
24 / \mathrm{Re} & \text { when } \operatorname{Re}<1 \\
24 / \mathrm{Re}+4 / \sqrt[3]{\mathrm{Re}} & \text { when } 1 \leq \operatorname{Re} \leq 10^{3} \\
0,48 & \text { when } 2 \cdot 10^{4} \leq \operatorname{Re} \leq 2 \cdot 10^{5}
\end{array} .\right.
$$




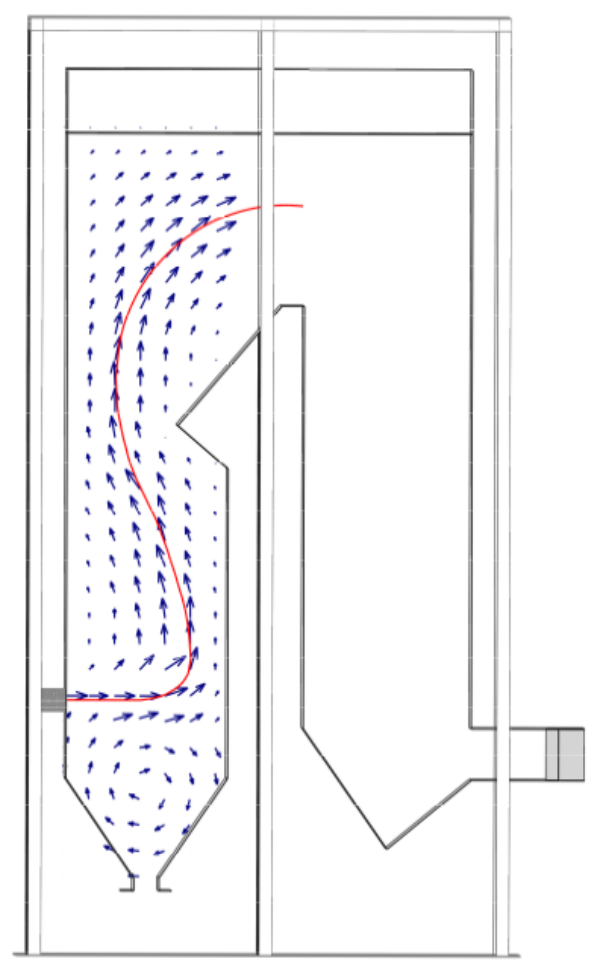

Fig. 6. Velocity vectors in boiler furnace E-230-14.0-520

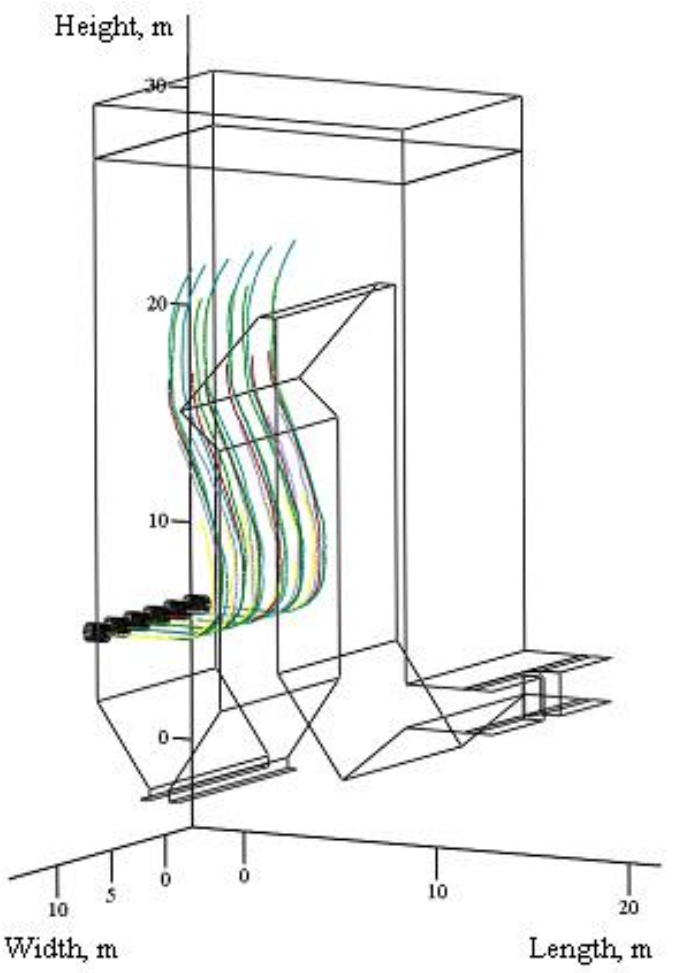

Fig. 7. Paths of motion of burning particles in boiler furnace E-230-14.0-520

System (9) with the known field of velocities is solved by means of a numerical method implemented in the environment of computer mathematic simulation. The paths of motion of reacting particles of characteristic sizes have been obtained as a result of calculations (Fig. 7).

\section{Digital designing of burning process}

The technologies utilizing computation equipment make it possible to give consideration to power engineering problems in more profound detailed manner with the use of a significant volume of iteration calculations. The detailed review of production processes at the stage of designing provides for a possibility of more precise (as compared with the use of absolutely standard methods) prediction of plant equipment operation indicators and, as a result, reduces capital investments, in future it will provide for reliable power supply of the consumers.

The economical efficiency of TPP operation, as the generating basis of the present-day power engineering of the world, determines macro scale conditions for full-scale permanent development of production facilities. The variable plant's expenditures get determined by fuel consumption and directly influence the economic indicators of its operation. When making thermal calculations of the boiler unit, a loss of heat from fuel mechanical underburning $\left(q_{4}\right)$ is adopted according to standard method of thermal design of boiler units. The value $q_{4}=1 \%$ has been adopted for the case under consideration. 
The numerical determination of $q_{4}$ can be performed with the use of dependences to calculate coal particle burning out. The coke mechanical underburning calculated for $1 \mathrm{~kg}$ of fuel $(G)$ can be determined for pulverized-coal flame according to formula:

$$
G=\frac{q_{4}}{100} \cdot \frac{Q_{\mu}^{p}}{Q_{\mathrm{K}}}
$$

where, $Q_{\mathrm{\kappa}}=8100 \mathrm{kCal} / \mathrm{kg}-$ coke combustion heat.

On the other hand $G$ can be presented as:

$$
G=K^{p} \cdot \int_{\left(\delta_{0 \mathrm{i}}\right)_{\tau}}^{\delta_{01}} b \cdot n \cdot \delta_{0 \mathrm{i}}^{n-1} \cdot e^{-b \cdot \delta_{0 \mathrm{i}}^{n}}\left(\delta_{\mathrm{i}} / \delta_{0 \mathrm{i}}\right)^{3} d \delta_{0 \mathrm{i}},
$$

where, $K^{\mathrm{p}}$ - relative contents of coke in as-received fuel; $\delta_{\mathrm{oi}}$ and $\delta_{\mathrm{i}}-$ initial and current size of particle of $i$-fraction, $\mathrm{m} ; \delta_{01}$ - initial size of the most coarse particle, $\mathrm{m} ;\left(\delta_{\mathrm{oi}}\right)_{\tau}-$ initial size of particle fully burnt by the moment of time $\tau$, at the end of which the particles continue to burn with the initial size exceeding $\left(\delta_{\mathrm{oi}}\right)_{\tau}, \mathrm{m} ; R_{\mathrm{oi}}$ - relative mass content (balance on a sieve) of particles with size equal or exceeding $\delta_{\mathrm{oi}}$, in the initial dust.

Thus, the value of $q_{4}$ will be determined according to dependence:

$$
q_{4}=K^{p} \cdot \int_{\left(\delta_{0 \mathrm{i}}\right)_{\tau}}^{\delta_{01}} b \cdot n \cdot \delta_{0 \mathrm{i}}^{n-1} \cdot e^{-b \cdot \delta_{0 \mathrm{i}}^{n}}\left(\frac{\delta_{\mathrm{i}}}{\delta_{0 \mathrm{i}}}\right)^{3} d \delta_{0 \mathrm{i}} \cdot \frac{Q_{\mathrm{\kappa}}}{Q_{H}^{p}} \cdot 100 .
$$

Integral (12) s admissible with respect to the initial size of the biggest particle, which according to [5] can be determined by the formula:

$$
\delta_{01}=(6.9 / b)^{1 / n}
$$

The value $\delta_{01}$ corresponds to mesh size of such a sieve, where the balance equals $0.1 \%$ of the mass of pulverized coal, i.e. when $R_{01}=0.1 \%$.

In order to determine $q_{4}$ according to provided algorithm, a computer program has been developed, which helps perform numerical evaluations of the amount of fuel mechanical underburning.

\section{Conclusive provisions and findings}

The up-to-date digital approaches to solving technical problems due to application of significant computational facilities make it possible to expand, deepen the spectrum of problem consideration. The results acquired by means of simulation reveal a more precise process pattern. Suchlike methods of investigation contribute to building a new generation of facilities bringing the human resources and, as a result, a possibility of occurrence of random errors to minimum at the stage of equipment designing. In this case, the accuracy of calculation results increases as much as the processes get studied with more details.

The simulation of polifractional solid fuel burning in the furnace chamber of boiler E230-14.0-520 has shown that the value of mechanical underburning adopted when making thermal design exceeds the design value by $0.5 \%$. It determines an increased fuel consumption and reduction of efficiency in the design boiler calculation. With the adopted value of mechanical underburning: $\eta=92.33 \%, B=38.2 \mathrm{t} / \mathrm{h}$; with calculated: $\eta=92.83 \%$, $B=38.0 \mathrm{t} / \mathrm{h}$. 
Thus, the developed model makes it possible to define more exactly the unit design characteristics and can be used both in the course of building new boilers, and during reconstruction and retrofitting, and upgrading thereof too. The calculation results conform properly to experimental data, which helps use the presented model for investigating the process of burning of hard organic fuel in case of its flame combustion.

\section{References}

1. A. Vasilyev, V. Lozhkin, D. Tarkhov, O. Lozhkina, V. Timofeev, IOP Conf. Ser.: J. Phys.: Conf. Ser., 919 (2017)

2. J. Kaikko, A. Mankonen, E. Vakkilainen, V. Sergeev, Energy Procedia, 120 (2017)

3. V. Babiy, V. Kuvaev, Combustion of coal dust and calculation of coal-fired torch (1986)

4. M. Khabarova, A. Trinchenko, Proc."Science week SPbSPU", 1 (2016)

5. V. Pomerantsev, K. Arefyev, D. Akhmedov, Basis of the practical theory of burning (1986)

6. M. Khabarova, M. Kadyrov, A. Trinchenko, Proc. "Science and innovations in technical universities" (2017)

7. A. Trinchenko, A. Paramonov, M. Kadyrov, A. Koryabkin, IOP Conf. Ser.: Earth Environ. Sci., 90 (2017)

8. A. Trinchenko, A. Paramonov, IOP Conf. Ser.: Earth Environ. Sci., 90 (2017)

9. A. Trinchenko, A. Paramonov, V. Skouditskiy, R. Anoshin, IOP Conf. Ser.: J. Phys.: Conf. Ser., 891 (2017) 